\title{
Difference of environment behind research and clinical practice between USA and Japan
}

\author{
Takefumi Komiya ${ }^{1,2}$, Gerard Chaaya ${ }^{3}$, Leigh Deshotels ${ }^{4}$, Andy Wang ${ }^{2}$ \\ ${ }^{1}$ Hematology/Medical Oncology, Thoracic/Research, Parkview Cancer Institute, Fort Wayne, IN, USA; ${ }^{2}$ Indiana University School of Medicine, \\ Indianapolis, IN, USA; ${ }^{3}$ Section of Hematology/Medical Oncology, ${ }^{4}$ Department of Internal Medicine, Tulane University School of Medicine, New \\ Orleans, LA, USA \\ Contributions: (I) Conception and design: T Komiya; (II) Administrative support: None; (III) Provision of study materials or patients: None; (IV) \\ Collection and assembly of data: T Komiya; (V) Data analysis and interpretation: T Komiya; (VI) Manuscript writing: All authors; (VII) Final \\ approval of manuscript: All authors. \\ Correspondence to: Takefumi Komiya, MD, PhD. Hematology/Medical Oncology, Thoracic/Research, Parkview Cancer Institute, 11050 Parkview \\ Circle, Fort Wayne, IN 46845, USA. Email: takefumi.komiya@parkview.com.
}

\begin{abstract}
Recent studies have demonstrated that there are differences among races in efficacy, tolerance and other outcomes in oncologic care. Some of these differences may be explained by different pharmacogenetics; however, social and environmental factors that can affect oncology practice are relatively underestimated. In this review we will focus on differences in environment, education and research between Japan and the US when it comes to lung cancer clinical practice. Such social differences seem to derive from historical reasons and continue to influence clinicians and researchers who manage lung cancer. Understanding the differences might help us conduct collaborative research in the future.
\end{abstract}

Keywords: Lung cancer; environment; clinical practice; education; research

Submitted Jun 27, 2019. Accepted for publication Jul 15, 2019.

doi: $10.21037 /$ jtd.2019.07.70

View this article at: http://dx.doi.org/10.21037/jtd.2019.07.70

\section{Introduction}

Development of new technology in oncology has changed the landscape in the management of lung cancer over the past few decades. Novel diagnostic and therapeutic modalities have been invented by both clinicians and scientists resulting in improved patient outcome; however, over 140,000 patients in the US still succumb to lung cancer annually (1). An international collaborative effort to develop novel treatments continues to be a paramount task for researchers. There are, however, some differences in environments among nations. Understanding the differences may help us promote such interactions between American and Japanese medical researchers.

Japanese academic system adopted western style in late $19^{\text {th }}$ century when Japan began to modernize its society after over 260 years of physical and economic isolation. Thereafter, medical infrastructure was primary built on academic institutions which later dominated medical society in Japan. After World War II Japan established a universal healthcare system in 1961 where most citizens hold health insurance (2). Healthcare expenditure per gross domestic product (GDP) cost remains below most developed nations while its national life expectancy is the longest. These environments are quite different, especially in the US where uninsured and underinsured people account for $12 \%$ and $28 \%$ of the population, respectively $(3,4)$.

Here we review differences in environments between the two nations which might have an impact on clinical practice, education and research. We hope our review will support investigators to understand other nations and form efficient collaborations in the future.

\section{Clinical practice}

Caregivers who manage lung cancer cases ideally offer 
multidisciplinary discussion. The care team should consist of a medical oncologist, pulmonologist, radiation oncologist, thoracic surgeon, pathologist, radiologist, palliative medicine and other ancillary staff members. These services are not always available at small institutions. In the US medical oncologists generally take the lead by managing patients and referring patients to appropriate specialty physicians. They may practice at academic, non-academic centers or small oncology outpatient offices in rural areas. Mid-level providers including nurse practitioners and physician assistants can help to reduce oncologists' workload. Acute care for oncologic emergencies is generally managed by emergency departments and inpatient units whereas other non-oncology medical providers (e.g., hospitalists) take primary role during their hospital stay. From a patient's perspective, access to medical institutions is very restrictive in the US. They are often directed to a specific medical facility due to their insurance status. If patients seek medical care at out-of-network institutions, patient's co-pay, co-insurance and overall out-of-pocket expense will be extremely higher than what they can pay at in-network institutions. Specialty clinic visits and outpatient procedures require prior preauthorization that might delay any diagnostic and/or therapeutic processes. Systemic treatment for lung cancer is primarily performed as an outpatient. Inpatient treatment is limited to palliative radiation and chemotherapy for small cell lung cancer specifically. Chemotherapy, immunotherapy and targeted therapy in non-small cell lung cancer are generally not offered for inpatients due to financial reasons.

The situation in Japan, however, is very different. Even large institutions allow walk-in visits to any subspecialty clinic including oncology. Universal healthcare system allows patients to visit any institution without appointment or additional charge. Annual rate of ambulatory clinic visit was $14 v s .2 .8$ in Japan and US, respectively, indicating the difference in access to healthcare institutions (5). Physicians who treat patients at outpatient clinics are expected to provide inpatient care simultaneously. Although this style maintains continuity of care, easy access to any medical institution certainly increases patient volume and pressure to providers which may lead to physician burnout phenomenon. Several physicians in their early career have committed suicide due to physical and psychological stress over the last decade (6). Lack of infrastructure to support working mothers has prevented female physicians from having children with physician partners. The Japanese government now promotes work style reform for physicians to improve their work environment (7).

Pattern in specialization remains different from western nations. According to our survey in 2017, medical oncology is not a well-established specialty in Japan $(8,9)$. The number of certified oncologists is relatively low as compared to other developed nations. Pulmonologists tend to perform both diagnostic and therapeutic procedures (e.g., ordering chemotherapy) for lung cancer patients. This practice pattern gives perfect continuity when patients transition from the diagnosis to treatment phase. Similarly other disease/site specific specialists manage systemic treatment in the cancer types that they perform diagnostic procedures for. For instance, breast surgeons can offer both breast biopsy and systemic therapy. Non-physician providers do not exist in Japan because prescription and independent medical management are permitted by law only for physicians. Even though certified medical oncologists have increased over the decades, the number per population remains quite lower than other nations (10). In a conservative society such as rural Japan where patients pay more respect to physicians and religiously follow providers' direction, continuity of care plays a critical role in medical care. It, however, contradicts the concept of specialization and task distribution which forms the style of medicine in the US. As international pressure and Japanese workstyle reform progresses, it is likely that continuity will be sacrificed in the future.

There are noticeable differences in physicians' compensation system. In the US, a physician's income depends on practice region and their chosen specialty. Specialties with higher incomes certainly tend to be more competitive. On the contrary, the salary of Japanese physicians at large centers is primarily based on postgraduation year. Differences in their specialty and practice location do not significantly impact their income. There are no financial incentives or bonuses paid by institutions.

\section{Education system}

At most academic institutions medicine in North America is taught as a four-year graduate education. Most students enter medical school after completing a four-year undergraduate program in a variety of majors. They are expected to show their motivation to medicine by doing volunteer work at medical institutions or shadowing established physicians. After completing a four-year undergraduate degree, some students may choose to take gap years before beginning medical school. Through these years, the students will 
gain valuable insight and experience and will begin medical school with a deeper understanding of another field of work or the field of medicine. The tradeoff is that they will graduate medical school at a relatively old age. Although they can seek financial aid and/or loans, rising costs in both undergraduate and graduate schools still give enormous pressure to the students. According to Nerdwallet.com, average student loan debt among medical graduates in 2018 was approximately $\$ 200,000$ (11). In addition, these students' schooling forces them to sacrifice additional years that could otherwise be spent earning money. These circumstances tempt students to choose specialties of high income or short post-graduate training period; therefore, entering post-graduate training programs of these specialties tends to be more competitive. International graduates coming from overseas especially have a difficult time matching in competitive specialty training. Once they are certified by the medical board, they generally remain in the same specialty throughout their medical career. Even though the number of female physicians increased in Japan, they represent much more in the US, leading to more physician couples. Although childcare is more established in US, physician parents still face hardships when they have children early in their career. Once they complete training they often stay in major US cities because it is not always possible for the couples to find specialty jobs in smaller cities. This trend applies to medical oncology as well where only $3.1 \%$ of oncologists practice in rural areas (12).

Medical oncology in the US has been one of the subspecialties in internal medicine over several decades. Its Accreditation Council for Graduate Medical Education (ACGME)-accredited training programs are commonly combined with hematology at teaching medical institutions. Medical oncology training programs, especially at academic institutions, are relatively competitive among other internal medicine subspecialties. Similar to other subspecialties, there are required infrastructures to execute and maintain the programs. ACGME monitors all programs and gives probation or termination to the programs that do not meet their requirements.

In contrast, both European and Japanese nations adopt six-year education after high-school graduation. Because most students in Japan decide to enter medical education at the age of 18 , they have very limited exposure to medicine prior to medical school. Acceptance by medical school is primarily based on scores of entrance examination. Candidates with the best scores at such a young age may not be committed to life-long medical education but may end up going to medical school just because they want to maintain their self-esteem. Postgraduate training system in Japan has long been uncontrolled. There had been no legally required period of post-medical school training in any medical specialty until the government finally mandated a two-year residency period in 2004 (13). Even though there are oncology training programs accredited by oncology organizations, a board-certification system is in the middle of its reform to meet the demand by its society.

Unlike in the US where obtaining specialty board certification is generally required for employment, a fulltime position in Japan can be obtained without such credentials. Their choice of specialty does not seem to be affected by the economy because the differences in income among specialties are minimal. For most graduates, there is no financial pressure to pay off student loans because costs for undergraduate and graduate education are generally low; annual tuition for public medical school is approximately $\$ 5,000$. Most people who complete initial residency choose specialty training at academic or large medical centers in major cities. Because private group practice with the same specialty is not common, only large medical centers provide them with opportunities to practice in their specialty. They need to compete with others to stay in large centers to remain in their field. Due to scarcity of opportunity or maybe fading interest, many physicians trained in any subspecialty eventually become primary care physicians in their mid-career. Ironically, maintaining their credentials such as medical license and specialty certificate is relatively easier in Japan. Medical license is valid for their lifetime throughout the country and no continuing medical education $(\mathrm{CME})$ is required to continue their practice. It allows many physicians in their late career to focus on general medicine after retiring from specialty medicine.

\section{Research}

In both nations, physicians at academic institution are expected to conduct medical research to gain new technology or knowledge in medicine. Whether its basic laboratory or clinical research, medical research requires funding for its execution. Maintaining financial resource is key to success in a research environment. In the US most institutions demand that researchers bring external funding to conduct their own research. Research grants are provided by organizations such as National Institutes of Health (NIH), Veterans Associations (VA) and private foundations. Physician-scientists who conduct laboratory research can 
have protected time for research during their work hours by obtaining external funds. With enough resources they can employ graduate students, research associates and/or postdoctoral fellows to perform daily bench research. However, the success rate in obtaining a federal grant has plummeted to nearly $10 \%$ over the decades making researchers financially unstable. Constant pressure to maintain funding is often overwhelming for academic researchers. In fact, even established researchers seek a career change to industry rather than stay in a competitive academic field.

Competition in a research environment looks different in Japan. Although they are also expected to have external funding, their research is often covered by an internal resource. They are not expected to pay for their work hours by an external research fund. Graduate students are assigned to researchers without compensation. Research staffs are often directly employed by a specific department so that investigators do not have to pay their salary. Nevertheless, many researchers are not financially independent within their department. They share resources under the direction of department chairs who are the only independent researchers in Japan. The number of department chair positions is limited leading to furious competition to reach them. Although becoming department chairs with power and independence continues to be a goal for Japanese researchers, their positions do not last long. All academic centers have a mandatory retirement age that physically limits their research toward the end of their career. With some exceptions most people must retire from government and large institutions by age 65 . In the US, however, there is no such mandatory retirement rule in any employment. The Age Discrimination in Employment Act of 1967 prohibits discrimination on the bases of age in employment. Many researchers remain in the field if their research is successful.

\section{Conclusions}

There are still significant differences between Japan and the US in circumstances surrounding oncologic care, education and research. These differences seem primarily due to nonscientific, historical reasons. Although efforts to modernize infrastructure in Japan continue, they will likely remain and influence oncologists. Economic and social incentives will be the keys to modernizing environments in Japan.

\section{Acknowledgments}

Funding: None.

\section{Footnote}

Provenance and Peer Review: This article was commissioned by the Guest Editors (Tomoya Kawaguchi and Phillip C. Mack) for the Series "Ethnic Difference in Lung Cancer" published in Fournal of Thoracic Disease. The article was sent for external peer review organized by the Guest Editors and the editorial office.

Conflicts of Interest: All authors have completed the ICMJE uniform disclosure form (available at http://dx.doi. org/10.21037/jtd.2019.07.70). The series "Ethnic Difference in Lung Cancer" was commissioned by the editorial office without any funding or sponsorship. The authors have no other conflicts of interest to declare.

Ethical Statement: The authors are accountable for all aspects of the work in ensuring that questions related to the accuracy or integrity of any part of the work are appropriately investigated and resolved.

Open Access Statement: This is an Open Access article distributed in accordance with the Creative Commons Attribution-NonCommercial-NoDerivs 4.0 International License (CC BY-NC-ND 4.0), which permits the noncommercial replication and distribution of the article with the strict proviso that no changes or edits are made and the original work is properly cited (including links to both the formal publication through the relevant DOI and the license). See: https://creativecommons.org/licenses/by-nc-nd/4.0/.

\section{References}

1. National Cancer Institute Surveillance, Epidemiology, and End Results Program. Cancer Stat Facts: Lung and Bronchus Cancer. Available online: https://seer.cancer.gov/ statfacts/html/lungb.html, accessed on April 21, 2019.

2. Zhang $X$, Oyama $T$. Investigating the health care delivery system in Japan and reviewing the local public hospital reform. Risk Manag Healthc Policy 2016;9:21-32.

3. Centers for Disease Control and Prevention. Health Insurance Coverage. Available online: https://www.cdc. gov/nchs/fastats/health-insurance.htm, accessed on April 21, 2019.

4. USA Today. Guess how many adults are underinsured. Available online: https://www.usatoday.com/story/money/ personalfinance/budget-and-spending/2017/11/23/guesshow-many-adults-are-underinsured/107709988/, accessed 
on April 21, 2019.

5. Tsuda T, Aoyama H, Froom J. Primary health care in Japan and the United States. Soc Sci Med 1994;38:489-95.

6. Doctor's suicide after monthly overtime exceeded 200 hours recognized as work-related. The Japan Times. August 10, 2017. Available online: https:// www. japantimes.co.jp/news/2017/08/10/national/socialissues/ doctors-suicide-monthly-overtime-exceeded-200-hoursrecognized-work-related/\#.XT9yfehKiUk, accessed on April 21, 2019.

7. Abe's work-style reforms give Japan's employers the green light to demand unpaid and unsafe overtime. The Japan Times. September 23, 2018. Available online: https:// www.japantimes.co.jp/community/2018/09/23/issues/ abes-work-style-reforms-give-japans-employers-greenlight-demand-unpaid-unsafe-overtime/\#.XULiouhKg2w, accessed on April 21, 2019.

8. Komiya T, Mackay CB, Chalise P. Status of oncologic specialties: global survey of physicians treating cancer. Int J Clin Oncol 2017;22:237-43.

Cite this article as: Komiya T, Chaaya G, Deshotels L, Wang A. Difference of environment behind research and clinical practice between USA and Japan. J Thorac Dis 2020;12(7):38043808. doi: $10.21037 /$ jtd.2019.07.70
9. Komiya T, Mackay CB, Chalise P. Who treats lung cancer? Results from a global survey. Respir Investig 2017;55:308-13.

10. Takiguchi Y, Sekine I, Iwasawa S, et al. Current status of medical oncology in Japan--reality gleaned from a questionnaire sent to designated cancer care hospitals. Jpn J Clin Oncol 2014;44:632-40.

11. Average Medical School Debt in 2018. Available online: https://www.nerdwallet.com/blog/loans/student-loans/ average-medical-school-debt/, accessed on April 25, 2019.

12. Kirkwood MK, Bruinooge SS, Goldstein MA, et al. Enhancing the American Society of Clinical Oncology workforce information system with geographic distribution of oncologists and comparison of data sources for the number of practicing oncologists. J Oncol Pract 2014;10:32-8.

13. Tokuda Y, Soshi M, Okubo T, et al. Postgraduate medical education in Japan: Missed opportunity for learning clinical reasoning. J Gen Fam Med 2018;19:152-3. 